\title{
EVIDÊNCIAS LITERÁRIAS DA PRÁTICA DAS AGOGAI ANTES DA ÉPOCA ROMANA
}

\author{
Cláudia Cravo \\ Univ. Coimbra - Faculdade de Letras da Universidade de Coimbra - Centro de Estudos Clássicos \\ e Humanísticos \\ claudiacravo@hotmail.com
}

\section{RESUMO}

Com base nos papiros mágicos gregos, não é possível provarmos a existência de encantamentos gregos de atracção (conhecidos como agogai) em tempos mais recuados. A falta de documentos reais anteriores à Época Romana é, felizmente, colmatada pela literatura grega, que nos deixou indícios suficientes da existência de práticas de magia erótica (em geral, e das agogai em particular) em épocas muito antigas. Deter-nos-emos nos três textos literários que consideramos mais significativos a este respeito e que nos deixam a garantia de que as agogai, tão famosas no mundo grego, têm de facto uma extraordinária e longa história.

PALAVRAS-CHAVE: magia erótica literária, agogai, papiros mágicos gregos.

\section{LITERARY EVIDENCE OF THE PRACTICE OF AGOGAI BEFORE THE ROMAN ERA}

\section{ABSTRACT}

Based on the Greek magical papyri, it is not possible to prove the existence of Greek charms of attraction (known as agogai) in earlier times. The lack of real documents prior to Roman Era is fortunately overcome by Greek literature, which left us sufficient evidence of the existence of erotic magic practices (in general, and agogai in particular) in very ancient times. We will focus on the three literary texts that we consider most significant in this matter and which leave us with the guarantee that agogai, so famous in the Greek world, do have indeed an extraordinary and long history.

KEYWORDS: literary love magic, agogai, Greek magical papyri.

Uma agoge é, como o próprio nome indica, um encantamento "que conduz/ que orienta/ que indica o caminho" ca frequente dos manuais de magia, designa um encantamento erótico de atracção que, através da violência e da tortura, tem como objectivo fazer com que uma pessoa (normalmente uma mulher) conceba uma paixão irremediável por outra pessoa (normalmente um homem), ao ponto de se sentir forçada a abandonar a sua própria casa para ir ao seu encontro. 
Aqui deixamos, desde logo, um exemplo ilustrativo deste tipo de práticas. $\mathrm{O}$ conjuro amoroso que passamos a citar é do séc. IV ou V d. C. e encontra-se em Papyri Graecae Magicae (PGM) 19a. É um encantamento, dirigido, como tantos outros, a uma entidade designada apenas por daimon, usado por um homem chamado Apalos, na tentativa de levar uma mulher, de nome Carosa, a vir ter com ele perdida de paixão:

Sim (...), trá-la, fá-la arder, destrói-a, queima-a, fá-la perder os sentidos enquanto é queimada e se inflama. Atravessa com um aguilhão a sua alma torturada (...) até que saia e venha para junto de Apalos, filho de Teonila, por paixão e por amor, agora mesmo, já, já, depressa, depressa! (...) Não deixes que ela, Carosa, filha de Teló, pense no seu marido nem no seu filho, nem na bebida, nem na comida, mas que venha derretida pela paixão, pelo amor e pela vontade de sexo, desejando mais do que tudo a companhia de Apalos, filho de Teonila. Agora, neste exacto momento! Já, já, depressa, depressa!

Dentro da magia erótica grega, as agogai são, de longe, o género mais popular, mais bem documentado. Muito embora existam oitenta e uma agogai publicadas, não podemos, no entanto, a partir dos papiros mágicos gregos, atestar a presença destes encantamentos de atracção em tempos mais recuados, uma vez que não existem testemunhos anteriores à Época Romana ${ }^{2}$. Este vazio é, felizmente, colmatado pela literatura grega, que nos deixou indícios suficientes da existência de práticas de magia erótica (em geral, e das agogai em particular) em épocas muito antigas.

Podíamos mencionar várias passagens literárias que reflectem, de forma mais ou menos óbvia, a existência de encantamentos de atracção desde os períodos mais recuados. Optámos, no entanto, por nos focar apenas nos três textos que consideramos mais significativos a este respeito e que nos deixam a garantia de que as agogai, largamente conhecidas no mundo grego, têm de facto uma extraordinária e longa história.

\section{SAFO, HINO A AFRODITE (FR. 1 LOBEL-PAGE)}

Safo deixou-nos uma composição poética que, não contendo propriamente alusôes à prática de magia erótica, é frequentemente (e bem!) associada às agogai que os papiros mágicos nos deram a conhecer, na medida em que reflecte a forma, o conteúdo e a intenção desses encantamentos amorosos reais ${ }^{3}$. Referimo-nos ao Hino a Afrodite, um poema repleto de ardente e angustiada paixão, em que Safo invoca Afrodite

${ }^{1}$ Palavra formada a partir do verbo grego agein.

${ }^{2}$ Como é sabido, os papiros mágicos são os documentos mais importantes para o estudo da magia grega. Ora, convém lembrar que o papiro mágico mais antigo conservado é do séc. I a. C. e não é de teor erótico. Do séc. I d. C. há apenas um feitiço de cariz amoroso, mas a grande maioria dos papiros gregos de magia pertencem aos séculos III e IV d. C., sobretudo a este último.

${ }^{3}$ Sobre esta questão, vide Cameron (1939), Segal (1974), Burnett (1983: 254-256), Faraone (1992) e Petropoulos (1993). 
e suplica a sua intervenção naquele momento em que sofre por um desejo insaciado. A poetisa recorda imagens das aparições anteriores da deusa em ocasióes idênticas e, subitamente, é a própria Afrodite que começa a falar (vv. 18-24):

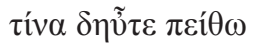

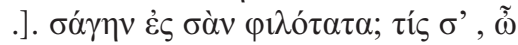

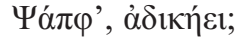

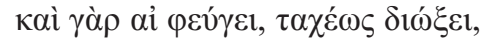

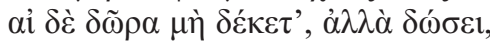

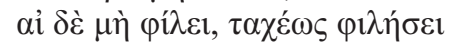

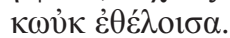

Quem de novo devo

convencer a voltar ao teu amor? Quem,

ó Safo, te faz mal?

Pois se foge, rapidamente perseguirá;

se não aceita os presentes, em vez disso os dará;

se não ama, rapidamente amará, mesmo que

ela o não queira ${ }^{4}$.

A deusa pergunta amavelmente a Safo quem é o actual objecto do seu desejo e promete-lhe que, tal como das outras vezes, também agora haverá de dar cumprimento aos seus propósitos e fazer com que o seu amor não correspondido passe imediatamente a merecer retribuição.

Se atentarmos, com algum cuidado, nos versos acabados de citar, facilmente encontramos vários ingredientes que justificam a frequente associação desta composição poética aos encantamentos eróticos de atracção tradicionais, ou seja, às agogai. Desde logo, o facto de Afrodite querer saber quem deve convencer, daquela vez, a amar a poetisa, implica que as preces que esta normalmente lhe dirige tenham sempre uma única finalidade: atrair a si o ente amado. Além disso, quando prediz a mudança da situação amorosa de Safo, nos vv. 21-24, a deusa utiliza uma formulação sintáctica que nos reporta, de imediato, para a linguagem dos textos mágicos reais. De facto, as várias proposições condicionais pronunciadas sob a forma de repetição antitética ('se .... então ...') assemelham-se a certas enunciações mágicas, como àquela que encontramos, por exemplo, em PGM 4. 1510-1520:

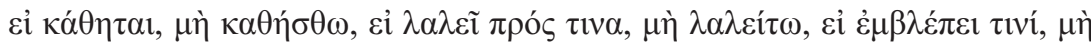

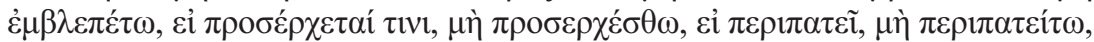

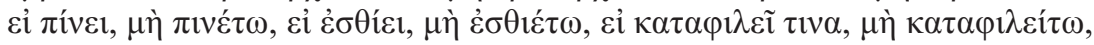

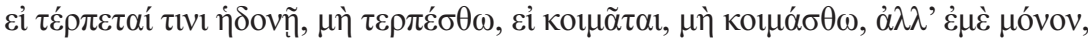

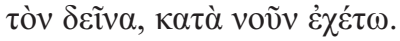

\footnotetext{
${ }^{4}$ Tradução de Lourenço (2020: 77-79).
} 
Se se senta, que não se sente; se fala com alguém, que não fale; se olha para alguém, que não olhe; se se aproxima de alguém, que não se aproxime; se passeia, que não passeie; se bebe, que não beba; se come, que não coma; se beija alguém, que não o beije; se se alegra com algum prazer, que não se alegre; se se deita, que não se deite; mas que só em mim, fulano, tenha o seu pensamento.

Voltando ao texto de Safo, também a reiteração do advérbio $\tau \alpha \chi \varepsilon ́ \omega \varsigma$, nos vv. 21 e 23, nos remete para o mundo da magia e, em particular, para os encanta-

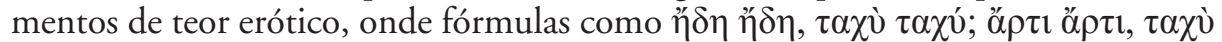
$\tau \alpha \chi u ́$ são extremamente comuns, reflectindo o princípio mágico de que a intervenção da divindade se deseja imediata.

No v. 24, Afrodite reafirma a sua pretensão de forçar a amada de Safo a amá-la

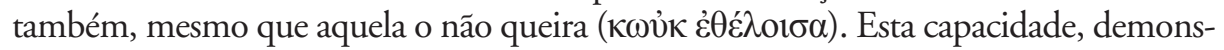
trada por Afrodite, de induzir uma pessoa a amar outra mesmo contra a sua vontade, figura também num hino à deusa, que aparece encaixado nos $P G M$ (em 4. 2934:

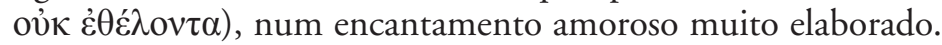

A orientação homossexual do poema de Safo é explícita. E é curioso notar que o amor entre pessoas do mesmo sexo também encontra expressão (embora em pequena escala) nos encantamentos de atracção que chegaram até nós. Segundo pudemos verificar, das oitenta e uma agogai publicadas, há três que são de índole homoerótica (SM 42, PGM 32 e PGM 32a).

Voltamos a ouvir a poetisa nos últimos versos da composição (25-28):

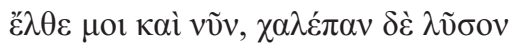

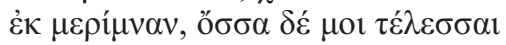

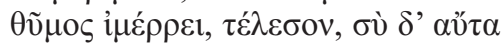

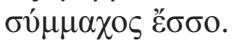

Vem até mim, agora também! Salva-me da aflitiva

ansiedade; e para mim faz cumprir tudo o que

meu coração deseja ver cumprido; e tu própria

combate ao meu lado! ${ }^{5}$

Também aqui é possível descobrirmos paralelos com a tradição grega de magia amorosa. O verbo $\tau \varepsilon \lambda \varepsilon i ̃ v$, usado por Safo nos vv. 26 e 27, aparece com muita frequência no final dos encantamentos eróticos de atracção. Faraone (1992) chamou a atenção para este facto e foi mais longe, ao interpretar o pedido de Safo (ő $\sigma \alpha \alpha \delta \varepsilon$

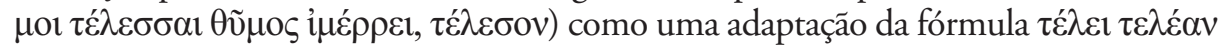
$\varepsilon \dot{\varepsilon} \alpha \propto \imath \delta \eta v$, típica da parte final de vários sortilégios eróticos reais, alguns dos quais dirigidos a Afrodite, como é o caso de PGM 4. $2939^{6}$.

\footnotetext{
${ }^{5}$ Tradução de Lourenço (2020: 79).

${ }^{6}$ Este assunto foi largamente explorado por Faraone, no artigo citado. A propósito, vide ainda, Faraone (1999: 136-137).
} 
Há alguns estudiosos que defendem a ideia de que as palavras de Safo pressupõem o acompanhamento de um acto mágico efectivo?. Não conhecemos as circunstâncias externas que rodeiam o Hino a Afrodite e, como tal, não podemos ir tão longe na argumentação. As evidências de que dispomos permitem-nos tão-somente concluir que as muitas afinidades sintácticas encontradas entre o poema em causa e o discurso de magia não serão, com toda a certeza, mera obra do acaso, ou seja, existirá uma base comum entre as palavras de Safo e uma longa tradição de encantamentos eróticos dirigidos a Afrodite.

\section{PÍNDARO, PÍTICA 4}

Mas a mais importante prova da antiguidade da prática das agogai encontramo-la em Píndaro, na sua Pítica 4. O poeta oferece-nos a primeira descrição detalhada de um rito de magia erótica. Conta-nos como, para ajudar Jasão a seduzir Medeia,

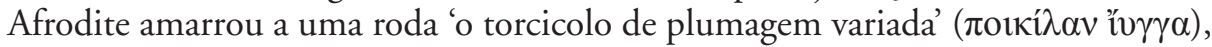
ligado pelos quatro membros. A deusa teria trazido do Olimpo este 'pássaro delirante' ( $\mu \alpha \imath \alpha_{\alpha} \delta$ 'ópvvv), para benefício dos homens e teria assim inventado um poderoso instrumento de magia erótica, com o qual Jasão poderia inflamar de desejo o coração de Medeia e convencê-la a segui-lo até à Grécia. Valerá a pena recordar o passo em questão (vv. 213-219):

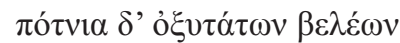

$\pi$ oıкí̇ $\alpha v$ "̌

$\dot{\varepsilon} v \dot{\alpha} \lambda \dot{\tau} \tau \omega \zeta \varepsilon v \dot{\xi} \alpha \alpha 1 \sigma \alpha \kappa v ́ \kappa \lambda \omega$

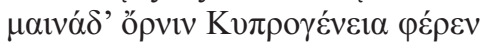

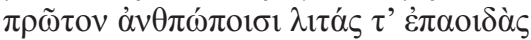

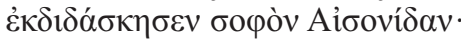

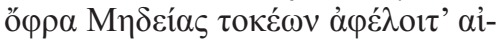

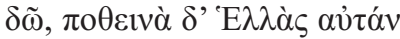

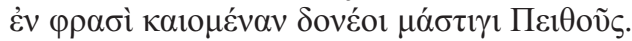

Mas a Soberana nascida na ilha de Chipre

prendeu o torcicolo aos quatro raios

da roda inelutável. Trouxe do Olimpo

aquele pássaro de loucura, pela primeira vez

aos homens, e ensinou o filho de Édson

a ser sábio em preces e encantamentos

para que ele pudesse acabar com o respeito de Medeia

pelos seus pais, e o desejo da Grécia pudesse

deixar a sua mente em chamas

e conduzi-la com o chicote da Persuasão.

${ }^{7}$ Vide, e. g., Petropoulos (1993: 54). 
Muitas são as afinidades existentes entre esta descrição do rito de magia erótica feita por Píndaro e as agogai preservadas nos documentos mágicos reais. Há excelentes estudos publicados sobre esta questão ${ }^{8}$, que será aqui resumida em breves tópicos, aqueles que, obviamente, consideramos mais pertinentes:

- Desde logo, interessa salientar que o procedimento mágico descrito por Píndaro alia a praxis ao logos, como é costume acontecer nos rituais de magia reais: quando falamos em praxis referimo-nos ao acto de amarrar o pássaro à roda e à manipulação da própria roda; quanto ao logos, é dito claramente que Afrodite ensinou a Jasão $\lambda i \tau \alpha \dot{c} \tau^{\prime} \dot{\varepsilon} \pi \alpha 01 \delta \alpha ̀ \zeta$.

- Estes versos constituem a primeira menção ao bizarro expediente mágico conhecido por iunx que encontraremos depois, repetidas vezes, nos ritos de magia erótica de atracção.

- Uma outra correspondência entre os versos de Píndaro e as agogai posteriores é a ideia de insanidade. O desejo sexual causado pelos encantamentos de atracção é comummente descrito como um louco frenesim. Píndaro descreve o pássaro iunx como 'louco' e dá ênfase ao adjectivo, recorrendo à técnica do encavalgamento ou transposição do verso. É também curioso notar que usa um adjectivo feminino ( $\mu$ aıvós), detalhe que sugere a transferência da loucura para Medeia, a quem o encantamento fará enlouquecer de desejo.

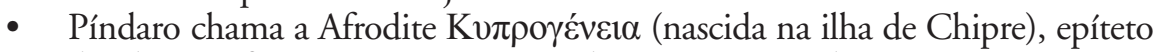
pelo qual a deusa é frequentemente invocada nas agogai tardias.

- Ao descrever os efeitos do encantamento de Jasão, Píndaro diz que Medeia será atacada com o 'chicote da (deusa) Persuasão'. Instrumentos de tortura como chicotes, aguilhões e outros, aparecem com frequência em encantamentos de atracção reais. Há muitos exemplos destas imagens de tortura. Deixamo-vos apenas um, bastante sugestivo, que contém um conjuro dirigido ao deus Anúbis (PGM 17a):

Anúbis, deus da terra e subterrâneo e celeste, cão, cão, cão, reúne todo o teu poder e toda a tua força contra Tigeró, nascida de Sofia. Póe fim à sua arrogância, ao seu entendimento e ao seu pudor. Traz-ma derretida pelo desejo amoroso a todas as horas do dia e da noite. Que sempre pense em mim, comendo, bebendo, trabalhando, falando, dormindo e sonhando; até que, aguilhoada por ti, venha desejando-me com as mãos cheias, com o seu bem dotado sexo, e oferecendo-se a si mesma (...) servindo o meu apetite e o seu, sem hesitação e sem pudor, músculo com músculo, ventre com ventre, e unindo a sua negrura com a minha, que é o maior prazer. Sim, Senhor, traz até mim a filha de Sofia, até mim, Hermeias, filho de Hermíone, já, já, depressa, depressa, impelida pelo teu aguilhão.

Mais correspondências encontraríamos entre a descrição de Píndaro e os feitiços reais conhecidos. Cremos, no entanto, estar provada a enorme importância destes versos da Pítica 4 enquanto eco da existência de uma tradição muito antiga de agogai.

${ }^{8}$ Vide, sobretudo, Faraone (1993) e Johnston (1995). 
Estas breves linhas de Píndaro são extremamente valiosas para a história da magia de teor erótico, na medida em que atestam, pela primeira vez, um encantamento amoroso de atracção (agoge), mas temos de esperar pela Época Helenística para nos ser concedida a oportunidade de assistir a uma minuciosa descrição literária das operaçôes típicas desta categoria de magia.

\section{TEÓCRITO, IDÍLIO 2}

Referimo-nos, obviamente, a Teócrito e ao seu Idílio 2, obra de peso excepcional na história da magia erótica, em geral, e na história das agogai, em particular.

A meio da noite, Simeta e a sua escrava Téstilis executam uma série de práticas mágicas com o objectivo de reconquistar o amor de Délfis, um jovem atleta que, durante algum tempo, fora amante de Simeta mas que entretanto a trocara por um novo amor. Todo o ritual mágico de atracção é relatado em pormenor, o que demonstra claramente que Teócrito estava familiarizado com as operações de magia usadas para atrair a pessoa amada, ou seja, com os procedimentos que envolviam as famosas agogai.

São, de facto, muitos (e de vária ordem) os paralelismos existentes entre o sortilégio erótico de Simeta e os encantamentos de atracção reais que encontramos nos papiros mágicos e nas defixiones.

Teócrito deixa claro, logo a partir do v. 10 (ao escolher a palavra $\theta u ́ o \varsigma)$, que a protagonista do seu idílio vai levar a cabo um encantamento de atracção no qual utilizará fogo, como é habitual acontecer nas agogai reais. Simeta diz: vĩv $\delta \dot{\varepsilon} v i v$

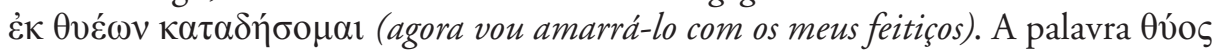
implica sempre uso do fogo, tanto em rituais mágicos como religiosos. Neste caso, refere-se, objectivamente, ao encantamento de teor amoroso que vai ter lugar momentos depois (vv. 17 sqq.), onde a jovem irá queimar substâncias tão diversas como farinha, louro, cera e uma franja do manto de Délfis, entre outras. A própria forma

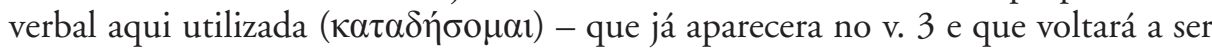
usada no v. 159 - reflecte a linguagem dos sortilégios amorosos reais. O verbo $\kappa \alpha \tau \alpha \delta \varepsilon ́ \omega$ é uma presença constante em encantamentos amorosos cuja intenção é, tal como no Idílio 2, prender a pessoa amada?.

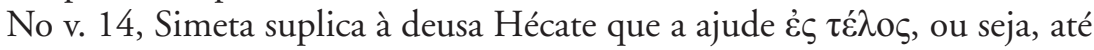
que se cumpra o propósito do encantamento mágico. Esta petição não é mais do que o refinamento literário de um conceito que, nas agogai reais, é expresso com o imperativo $\tau \dot{\lambda} \lambda \varepsilon \sigma o v$. De facto, quando alguém, nos papiros mágicos, pede a uma divindade

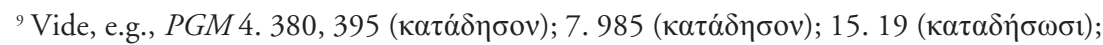

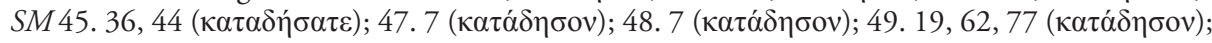
e ainda $D T 49$, onde a palavra $\kappa \alpha \tau \alpha \delta \tilde{\omega}$ é repetida nove vezes. 
que realize determinada acção sobrenatural, como acontece aqui, utiliza habitualmente o verbo $\tau \varepsilon \lambda \varepsilon^{10} \omega^{10}$.

Ao longo da série de estrofes que compõem a cena de encantamento, que ocupa os vv. 17-63, Simeta vai desenvolver todo um ritual de agoge, na tentativa de atrair Délfis até sua casa. A jovem mulher recorre, com insistência, a um tipo comum de fórmula mágica (a que é vulgar chamar-se similia similibus) em que aquele que executa o feitiço procura transferir uma determinada acção ou um estado de uma substância que tem em seu poder para uma outra substância ou, mais frequentemente, para uma pessoa.

Recordemos alguns momentos do dito ritual, que é intercalado regularmente por um verso-refrão, em que Simeta reitera a sua intenção: Roda mágica, atrai

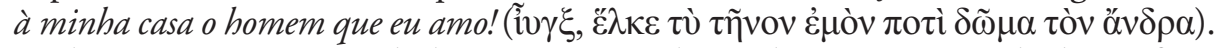
Facilmente conseguimos idealizar uma jovem louca de paixão, empenhada em fazer girar, em intervalos regulares, uma pequena roda que - acreditava ela - teria o poder de atrair o homem amado. E a iunx não é o único instrumento de atracção que Simeta vai usar na tentativa de recuperar o amante perdido. Mais à frente, no v. 30, ela faz girar um rombo de bronze, ao mesmo tempo que exprime o desejo de que o homem amado descreva um movimento semelhante até sua casa.

A primeira acção ritual (vv. 18-21) consiste em lançar ao fogo farinha de cevada ( $\alpha \dot{\alpha}(\varphi \imath \tau \alpha)$, ingrediente que funciona aqui como símbolo dos ossos do amado infiel. As ordens de Simeta são muito claras: ao mesmo tempo que faz arder a ceva-

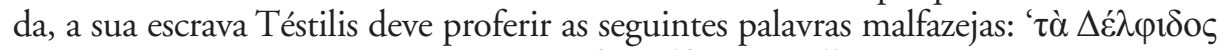

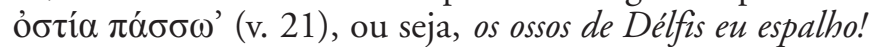

Levado a efeito pela própria Simeta, o segundo rito (vv. 23-26) é uma expansão do primeiro. O louro que é queimado representa a carne de Délfis, que a jovem quer ver consumir-se no fogo, tão rapidamente como a planta: $E$ assim como o louro crepita no fogo vivamente e nele, de repente, se consome, sem que vejamos sequer a sua cinza, assim também a carne de Délfis nas chamas se desfaça!

Nos vv. 28-31, a jovem feiticeira faz derreter cera para que, analogicamente, Délfis se derreta de amor por ela. A questão que aqui se levanta é saber se a cera mencionada pela jovem feiticeira se encontra ou não modelada em figurinha. $\mathrm{O}$ texto não contém nenhuma indicação que nos permita esclarecer esta dúvida, mas a maioria da crítica defende que o mais provável é mesmo que Simeta seja detentora de uma imagem de cera representativa do amante infiel. Como se sabe, o uso de estatuetas (de chumbo, bronze, barro, cera, etc.) em contextos mágicos foi, desde sempre, um fenómeno muito comum, em particular na magia erótica de atracção ${ }^{11}$.

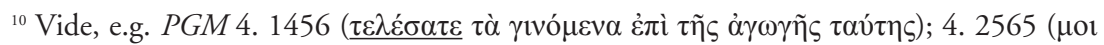

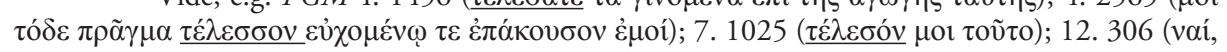

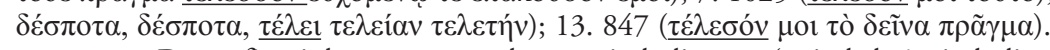

${ }^{11}$ Destas figurinhas, que normalmente simbolizavam (e ainda hoje simbolizam!) a "vítima", ou seja, o inimigo pessoal ou aquele que é objecto do desejo de quem pratica o ritual de encantamento amoroso, chegaram até aos nossos dias variadíssimos exemplares, alguns deles muito antigos, oriundos 
Nos vv. 43-46, Simeta dirige-se a Hécate nestes termos: Três vezes faço uma libação e três vezes, Soberana, pronuncio estas palavras: quer seja mulher, quer seja homem que com ele dorme agora, que um tão grande esquecimento invada Délfis como aquele que - ao que dizem - fez Teseu esquecer, em Dia, Ariadne de belas tranças.

O número três tem um valor mágico inegável, normalmente justificado pelo facto de ser o primeiro número ímpar (se exceptuarmos, como é óbvio, a unidade) e de às forças sobrenaturais agradarem estes números, que são indivisíveis por dois e, como tal, dotados de um grande poder. É impossível ignorar a presença insistente do número três ao longo dos mais diversos documentos que atestam práticas mágicas. De acordo com variadíssimas prescrições dos papiros, determinadas acções e fórmulas rituais devem ser repetidas três vezes ou reproduzidas segundo um número múltiplo de três: e. g. PGM 12.307 (e quando terminares esta fórmula, di-la três vezes cada dia, na hora terceira, sexta e nona) ou 13.237 (para uma 'agoge', dirige ao sol três vezes estas palavras...).

A jovem feiticeira expressa o seu desejo de que um grande esquecimento se apodere do homem que ama. Délfis deverá apagar da memória a sua actual companhia e voltar a bater à sua porta. A acção da magia sobre a memória é um motivo muito explorado desde os tempos mais antigos e há-de vir a aparecer, com frequência, em textos ligados a rituais de magia erótica de atracção. Uma defixio ática, datada do séc. IV a. C., estabelece que um certo Cárias venha a esquecer a sua amada Teodora, bem como o filho desta ${ }^{12}$. Vários papiros mágicos repetem um tipo característico de feitiços amorosos que têm como objectivo provocar o esquecimento de antigos relacionamentos, tal como acontece neste passo de Teócrito. A fórmula normalmente utilizada assenta no que podemos designar por 'amnésia selectiva': a "vítima" deve esquecer a sua família, amigos e/ou amantes e ter na mente apenas o indivíduo (homem ou mulher) que executa o encantamento. Recordemos, a título de exemplo, PGM 61. 29-30: que se esqueça de seu pai e de sua mãe e de seus irmãos e de seu marido e de seu amigo; excepto de mim, que se esqueça destes todos. E não podemos deixar de citar PGM 4. 2740-2744, onde encontramos uma prece muito semelhante à de Simeta, mas aqui articulada por uma voz masculina: se está deitada no regaço de outro, que o rejeite e me coloque a mim no seu coração e, quando o deixe, que imediatamente se apresente às portas da minha casa, dominada pelo desejo do meu amor e do meu leito.

O ritual mágico continua, com Simeta a exprimir, nos vv. 48-51, o desejo de que Délfis chegue a sua casa completamente louco de amor, assim como ficam as éguas por acção do hipómanes ${ }^{13}$. Em seguida, queima uma franja do manto do amado (vv. 53-54): Do seu manto, Délfis perdeu esta franja, que eu agora, fio a fio, lanço

dos mais diversos locais espalhados pelo mundo grego e romano. Num longo estudo que dedicou ao uso de figurinhas na Grécia antiga, Faraone (1991) apresenta, em apêndice, o catálogo de todas as "private voodoo dolls" gregas, etruscas e romanas que sobreviveram até aos nossos dias.

${ }^{12}$ DT 68. As circunstâncias que envolvem esta defixio são desconhecidas.

${ }^{13}$ Sobre esta curiosa substância afrodisíaca, vide Cravo (2014). 
no fogo voraz. A intenção desta prática é evidente e decorre da crença generalizada de que um objecto (ou parte de um objecto) que tenha estado em contacto com o corpo de um indivíduo permite exercer uma acção sobre ele. Desta forma se explica que a utilização de roupa (ou de fragmentos de roupa) da pessoa amada seja muito frequente em contextos de magia erótica de atracção.

E a cerimónia mágica vai terminar com um toque de malvadez e de tortura, tão ao jeito das agogai reais que chegaram até nós. São estas as palavras de Simeta na última estrofe do sortilégio amoroso (vv. 58-62): Vou esmagar um lagarto e levar-lhe amanhã uma poção maligna. Mas agora, Téstilis, toma tu estas ervas mágicas e amassa-as, às escondidas, sobre a soleira da sua casa, enquanto ainda é de noite, escarra e diz depois: "eu amasso os ossos de Délfis».

Concluiremos a enumeração dos paralelismos existentes entre o sortilégio erótico de Simeta e os encantamentos de atracção reais, chamando a atenção para um pormenor curioso, que, ao que nos parece, tem passado despercebido aos estudiosos deste poema.

O ritual de agoge protagonizado por Simeta é precedido por uma invocação inesperada. Após declarar que os seus encantamentos serão dirigidos a Selene e a Hécate infernal, Simeta solicita a ajuda desta última, da seguinte forma (vv. 14-16): Salve, ó Hécate terrivel!' Assiste-me até ao fim para que estas drogas sejam tão fortes como as de Circe, ou de Medeia ou da loura Perimede.

Esta é a primeira vez que testemunhamos a ligação de um encantamento erótico de atracção a uma divindade habitante no submundo. E Simeta invoca Hécate na sua vertente mais assustadora, tal como é comum acontecer nas agogai da Época Romana. Ela é a Hécate infernal, diante da qual até os cães tremem, quando passa por entre os túmulos dos mortos... (v. 12).

Inúmeros são os exemplos de agogai tardias que invocam ou mencionam divindades do reino das sombras, sobretudo Hécate, Perséfone e Hermes. No Período Romano, Selene encontra-se assimilada a Hécate, na sua forma ctónica de superintendente dos mortos, e é também invocada em vários sortilégios de teor erótico. Não sabemos exactamente quando se terá dado esta assimilação, mas a verdade é que as duas divindades já aparecem lado a lado, naturalmente associadas, no Idílio 2 de Teócrito.

Em suma, e em jeito de conclusão, cabe-nos dizer que os inúmeros pontos de contacto entre o texto teocritiano e os documentos de magia erótica posteriores deixam claro que o poeta fez uso de material pertencente a uma tradição antiga de encantamentos de atracção, uma tradição muitíssimo anterior ao seu tempo, que, embora não possa ser provada por testemunhos reais, já se encontra reflectida no Hino a Afrodite de Safo e, dois séculos mais tarde, é claramente atestada por Píndaro na sua Pitica 4.

\section{BIBLIOGRAFIA}

Audollent, A. (ed.) (1904): Defixionum Tabellae, Paris [= DT].

Burnett, A. P. (1983): Three Archaic Poets. Archilochus, Alcaeus, Sappho, London. 
Cameron, A. (1939): «Sappho’s prayer to Aphrodite», HThR 32: 1-17.

Cravo, C. (2014): «Hipómanes: um lugar-comum da magia erótica literária», em A. MARTínEZ FERNÁNdez - B. Ortega Villaro - H. Velasco lópez - H. Zamora Salamanca (eds.), Ágalma. Homenaje a Manuel García Teijeiro, Valladolid, 993-1000.

Daniel, R. W. - Maltomini, F. (1990-1992): Supplementum Magicum. Papyrologica Coloniensia XVI, 1 and 2, Opladen. 2 vols. [= SM].

FARAONE, C. A. (1991): «Binding and burying the forces of evil: The defensive use of "voodoo dolls" in Ancient Greece», ClAnt 10: 165-205.

FARAONE, C. A. (1992): «Aristophanes, Amphiaraus, Fr. 29 (Kassel-Austin): oracular response or erotic incantation?», CQ 42: 320-327.

FARAONE, C. A. (1993): «The wheel, the whip and other implements of torture: erotic magic in Pindar Pythian 4. 213-19», CJ 89: 1-19.

Gow, A. S. F. (1965): Theocritus, Cambridge. 2 vols.

Johnston, S. I. (1995): «The song of the Iynx: magic and rhetoric in Pythian 4», TAPhA 125: 177-206.

Lobel, E. - Page, D. L. (1963): Poetarum Lesbiorum Fragmenta, Oxford.

Lourenço, F. (2020): Poesia Grega de Hesiodo a Teócrito, Lisboa.

Petropoulos, J. C. B. (1993): «Sappho sorceress: another look at frag.1 (L-P)», ZPE 97: 43-56.

Preisendanz, K. (ed.) (1973): Papyri Graecae Magicae. Vol. I. Stuttgart. [1 a ed. 1928, Leipzig \& Berlin] $[=P G M]$.

Preisendanz, K. (ed.) (1974): Papyri Graecae Magicae. Vol. II. Stuttgart. [1ª ed. 1931, Leipzig \& Berlin] [ $=P G M]$.

Race, W. H. (1997): Pindar. Olympian Odes. Pythian Odes, Cambridge, Mass.

SEgAL, C. (1974): «Eros and incantation: Sappho and oral poetry», Arethusa 7.2: 139-160. 
